OPEN ACCESS

Edited by:

Julio Parra-Flores,

University of the Bío Bío, Chile

Reviewed by:

Zhao Chen,

Clemson University, USA

Ariadnna Cruz-Córdova,

Hospital Infantil de México Federico

Gómez, Mexico

*Correspondence:

Carmen Losasso

closasso@izsvenezie.it

${ }^{\dagger}$ These authors have contributed equally to this work

Specialty section:

This article was submitted to

Food Microbiology,

a section of the journal

Frontiers in Microbiology

Received: 09 August 2016 Accepted: 05 October 2016 Published: 20 October 2016

Citation:

Pezzuto A, Belluco S, Losasso C,

Patuzzi I, Bordin P, Piovesana A, Comin D, Mioni R and Ricci A (2016) Effectiveness of Washing Procedures

in Reducing Salmonella enterica and Listeria monocytogenes on a Raw Leafy Green Vegetable (Eruca vesicaria). Front. Microbiol. 7:1663. doi: 10.3389/fmicb.2016.01663

\section{Effectiveness of Washing Procedures in Reducing Salmonella enterica and Listeria monocytogenes on a Raw Leafy Green Vegetable (Eruca vesicaria)}

\author{
Alessandra Pezzuto ${ }^{1 \dagger}$, Simone Belluco ${ }^{2,3 t}$, Carmen Losasso ${ }^{2 *}$, Ilaria Patuzzi 2,4 , \\ Paola Bordin' ${ }^{2}$, Alessia Piovesana ${ }^{1}$, Damiano Comin ${ }^{1}$, Renzo Mioni ${ }^{1}$ and Antonia Ricci ${ }^{2}$ \\ ${ }^{1}$ Optimization and Control of Food Production Laboratory, Istituto Zooprofilattico Sperimentale delle Venezie, San Donà di \\ Piave, Italy, ${ }^{2}$ Department of Food Safety, Istituto Zooprofilattico Sperimentale delle Venezie, Legnaro, Italy, ${ }^{3}$ Department of \\ Animal Medicine, Production and Health, Università di Padova, Padova, Italy, ${ }^{4}$ Department of Information Engineering, \\ Università di Padova, Padova, Italy
}

Vegetables are an important source of nutrients, but they can host a large microbial population, particularly bacteria. Foodborne pathogens can contaminate raw vegetables at any stage of their production process with a potential for human infection. Appropriate washing can mitigate the risk of foodborne illness consequent to vegetable consumption by reducing pathogen levels, but few data are available to assess the efficacy of different practices. In the present work, six different washing methods, in the presence or absence of sanitisers (peracetic acid and percitric acid, sodium bicarbonate, sodium hypochlorite) and vinegar, were tested for their effectiveness in reducing Salmonella and Listeria counts after artificial contamination of raw rocket (Eruca vesicaria). Results showed that washing with sodium hypochlorite (200 mg/L) was the only method able to produce a significant 2 Log reduction of Salmonella counts, but only in the case of high initial contamination ( $7 \mathrm{Log} \mathrm{CFU} / \mathrm{g}$ ), suggesting potential harmful effects for consumers could occur. In the case of Listeria monocytogenes, all the examined washing methods were effective, with $200 \mathrm{mg} / \mathrm{L}$ sodium hypochlorite solution and a solution of peracetic and percitric acids displaying the best performances ( 2 and 1.5 Log reductions, respectively). This highlights the importance of targeting consumers on fit for purpose and safe washing practices to circumvent vegetable contamination by foodborne pathogens.

Keywords: consumer phase, food safety, fresh produce, microbiological risk, Salmonella, Listeria

\section{INTRODUCTION}

Vegetables are an important source of dietary fiber, vitamins and minerals, have low energy density and provide a range of nutrients that are required to regulate the body's metabolic functions. For these reasons, dietary guidelines recommend a high intake of vegetables (WHO/FAO, 2003).

However, due to their high surface/weight ratio and relatively high $\mathrm{pH}$, salad vegetables host large microbial populations, particularly bacteria, which contribute to the natural decay of 
vegetative organs detached from the plant (Ragaert et al., 2007). Human pathogens such as Listeria monocytogenes, Salmonella, and Escherichia coli O157:H7 can contaminate foodstuffs both during plant cultivation and processing (Francis et al., 1999; Brandl, 2006; Franz and van Bruggen, 2008).

Evidence of fresh produce-associated foodborne illnesses has been growing in recent decades and the description of such outbreaks is common in the United States and elsewhere (Berger et al., 2010), despite the prevalence of the main pathogens continuing to be low in fruit and vegetables (EFSA, 2015; Denis et al., 2016). However, outbreaks of illness associated with vegetables and juices have been increasing in recent years, rising from $4.4 \%$ in 2013 to $7.1 \%$ in 2014 (EFSA, 2015). Salmonella spp. and Listeria spp. are of major concern, due to the high number of cases and to the severity of the related harm, respectively (EFSA, 2015).

Salmonella enterica is an enteric, Gram negative pathogen which can contaminate fresh produce through various routes, including via use of organic waste as fertilizer, contamination of irrigation waters with fecal material, direct contamination by livestock and wild animals and hygiene errors in handling and processing (Heaton and Jones, 2008). L. monocytogenes is a ubiquitous Gram positive pathogen frequently isolated from food processing plants and recognized as an important agent of cross-contamination during food handling at both industrial and domestic levels (Lomonaco et al., 2015).

The risk derived from contaminated foodstuffs is increased for YOPIs (Young, Old, Pregnant, Immunocompromised) due to their high susceptibility and, thus, the possibility for disease to be more severe. The increased importance of fresh produceassociated foodborne illnesses has directed the attention of the scientific community toward the implementation of mitigation strategies able to prevent such cases (Chen and Jiang, 2014).

Despite the growing consumption of ready-to-eat vegetables, raw vegetables are still widely consumed in the European Union. This consumption pattern means the measures taken by consumers play a critical role in the prevention of foodborne diseases, as the consumption phase is the last step in the "farm to fork" chain and the only one beyond the official checks performed by the competent authorities involved in assuring food quality. However, according to the scientific literature, consumers are frequently unaware of their role in the prevention of foodborne diseases and underestimate the incidence and severity of such diseases (Losasso et al., 2012). Moreover, it has been shown that improved knowledge allows consumers to make informed choices regarding their actions and, consequently, the accuracy and the extent of information acquired by consumers could be of major significance in foodborne illness mitigation strategies (Losasso et al., 2012, 2013; Faccio et al., 2013).

Among mitigation strategies, sanitation treatments can play an important role in reducing pathogen levels on fresh vegetables. Application of a detergent before disinfection may help remove microbes from the surface of fresh produce (Gil et al., 2009). Most investigations concerning the efficacy of disinfectants for reduction of pathogenic bacteria have been conducted on inoculated fresh fruits ( Liao and Sapers, 2000; Bastos et al., 2005; Sy et al., 2005) or vegetables (Hilgren and Salverda, 2000;
Hellström et al., 2006). Among these studies, chlorine has proved to be one of the best candidate disinfectants, in association with surfactants.

In response to the current public health concerns associated with the microbiological safety of fresh produce, the aims of the present study were to: (1) assess vegetable sanitation strategies used by consumers, and; (2) determine the efficacy of identified common sanitisers at the consumer and industrial levels for reducing Salmonella and Listeria in fresh vegetables, taking Eruca vesicaria (rocket) as a case study.

\section{MATERIALS AND METHODS}

\section{Study Design}

The study was divided into two phases. In the first phase, two independent surveys were performed to collect information regarding raw vegetable handling and washing methods in the domestic and industrial environments. Results were used to design the second phase of the study, where real life scenarios for raw vegetable management were evaluated for their effectiveness in reducing S. enterica and L. monocytogenes contamination.

\section{Survey of Domestic Raw Vegetable Washing}

A questionnaire was administered to a sample of consumers selected on a voluntary basis by snowball sampling. Due to defections that normally occur when people participate on a voluntary basis, not all the subjects answered all the proposed questions. The questionnaire consisted of four questions and is available on request. Questions aimed to collect information about vegetable washing in the domestic environment, paying particular attention to:

- washing methods (immersion, running water, other);

- duration of the washing operation (less or more than $5 \mathrm{~min}$ );

- number of washing sessions (one, two, three, or more);

- chemicals added to the wash water (vinegar, sodium bicarbonate, common salt, commercial products, none, others).

\section{Survey of Industrial Raw Vegetable Washing}

A survey was conducted to investigate the principal industrial vegetable washing methods by interviewing 20 producers of ready-to-eat vegetables located in the northeast of Italy.

\section{Washing Protocols}

The survey of domestic and industrial methods for leafy green washing and sanitation identified six washing methods that were investigated through an experimental study aimed at assessing their effectiveness in the reduction/elimination of previously inoculated L. monocytogenes and S. enterica.

The selected washing protocols were:

- washing protocol 1 (WP1): 3 min immersion in an acidic solution (peracetic acid + percitric acid provided by one 
of the industrial vegetable producers) followed by a $3 \mathrm{~min}$ rinse with tap water (chlorine residue $<0.2 \mathrm{mg} / \mathrm{l}$ as required by National D. lgs 31/01);

- washing protocol 2 (WP2): a single 3 min immersion in tap water;

- washing protocol 3 (WP3): WP2 repeated three times (i.e., in three baths of fresh tap water);

- washing protocol 4 (WP4): 15 min immersion in sodium bicarbonate $(2.5 \%)$;

- washing protocol 5 (WP5): $3 \mathrm{~min}$ immersion in a 5\% solution of vinegar (vinegar acidity level 6\%) in water;

- washing protocol 6 (WP6): 15 min immersion in a solution of sodium hypochlorite $(200 \mathrm{mg} / \mathrm{L})$ followed by a tap water rinse.

\section{Sample Preparation}

Unpacked raw rocket (E. vesicaria) was obtained from a local retail store. The rocket used did not contain any detectable Salmonella or Listeria.

Experimental units were composed of $25 \mathrm{~g}$ of rocket. For experimental washing trials, two units were pooled before inoculation to have enough material to carry out both quantitative and qualitative microbiological analysis (Figure 1).

Two S. enterica suspensions were prepared in order to obtain a final microbial load of 3 and $7 \mathrm{Log}$ CFU/g. Suspensions were prepared starting from a mix of three different $S$. enterica isolates belonging to different serovars: S. Agbeni (CNRS 463/S03), S. Give (4509/2013), and S. Derby (4532/2013). The stock cultures were subcultured on tryptone agar slants at $4^{\circ} \mathrm{C}$, and Salmonella serovars were confirmed by serotyping according to Grimont and Weill (Grimont and Weill, 2007). The Salmonella were then transferred to $15 \mathrm{ml}$ of MuellerHinton broth (MHB) and incubated at $37^{\circ} \mathrm{C}$ overnight. Two L. monocytogenes suspensions were prepared in order to obtain a final microbial load of 6 and 7 Log CFU/g starting from a mix of one ATCC isolate (ATCC 13932) and two wild isolates from animal matrices. All Salmonella and Listeria isolates belonged to the collection of pathogenic microorganisms held by the Istituto Zooprofilattico Sperimentale delle Venezie (Legnaro, Italy).

Rocket (25 g) was inoculated with $1 \mathrm{ml}$ of suspension containing $S$. enterica or L. monocytogenes and subsequently washed with one of the six washing methods identified by the surveys ( see Washing Protocols, above).

\section{Microbiological Analyses}

Microbiological analyses were performed in triplicate according to standard methods. Salmonella qualitative analysis was carried out according to ISO 6579:2002/Cor.1 2004 (E) (ISO, 2004b). Salmonella quantitative analysis was carried out according to a spread plating method developed in-house: $25 \mathrm{~g}$ of rocket were suspended in $225 \mathrm{~g}$ of buffered peptone water, and $100 \mu \mathrm{l}$ of suspension and subsequent dilutions were spread plated on XLD (Xylose-Lysine-Deoxycholate) agar. XLD agar plates were incubated at $37^{\circ} \mathrm{C}$ for $24 \mathrm{~h}$ and then Salmonella colonies were counted. The detection limit for this quantitative method was $10 \mathrm{CFU} / g$. Listeria qualitative analysis was carried out according to ISO 11290-2:1998/Amd 12004 (ISO, 2004a). Listeria quantitative analysis was carried out according to UNI EN ISO 11290-1:2005 (UNI EN ISO, 2005).

\section{Statistical Analysis}

Descriptive analysis was performed in $\mathrm{R}$ environment (version 3.2.2). The data were log-transformed and displayed in the form of two scatter plots (Weissgerber et al., 2015) (one for Salmonella and one for Listeria) containing the outcomes of all examined contamination levels (7 and $3 \mathrm{Log} \mathrm{CFU} / \mathrm{g}$ for Salmonella and 7 and $6 \mathrm{Log}$ CFU/g for Listeria). A linear mixedeffects model that allows for inclusion of random effects was used to detect statistically significant differences (significance level of 0.05) among washing methods. In this framework, the withinreplicate errors are allowed to be correlated and/or have unequal variances. The analysis was performed using nlme package in $\mathrm{R}$ environment.

\section{RESULTS}

\section{Survey of Domestic Raw Vegetable Washing}

Varying numbers of respondents, from 125 to 190 for each question, filled in the four administered questions. The results are reported in Figure 2. The most common vegetable sanitation practices were: washing vegetables three times or more; by immersion; for more than $5 \mathrm{~min}$; without any chemicals added to the wash water (Figures 2A-D). Moreover, a minor percentage of respondents reported using sodium bicarbonate or vinegar for vegetable sanitation (Figure 2D).

Four washing methods proved to be the most commonly used by consumers: immersion of rocket in tap water one time;

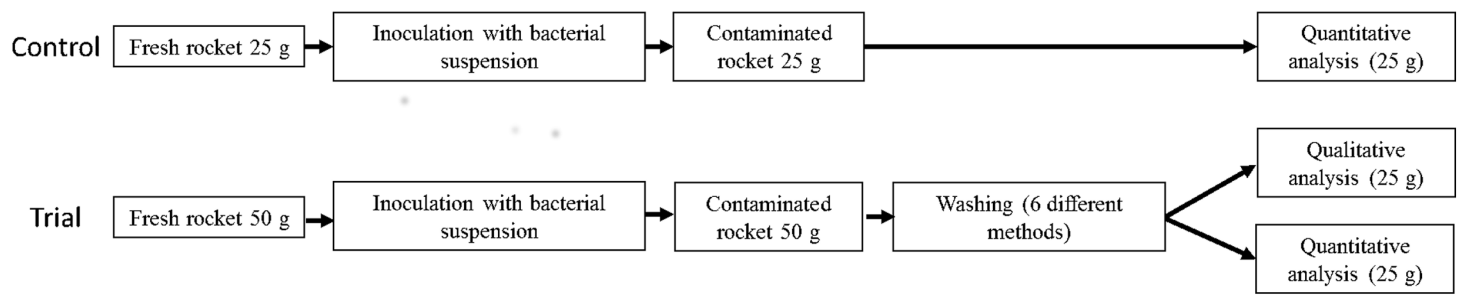

FIGURE 1 | Flowchart describing the study design of experimental trials. 


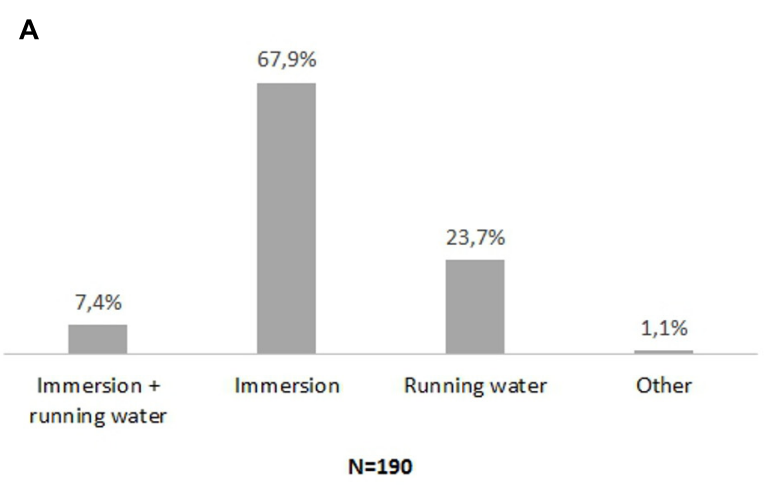

C

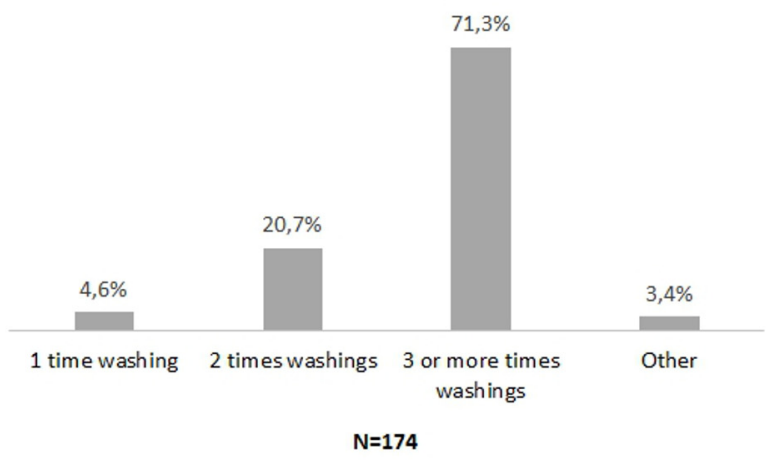

B

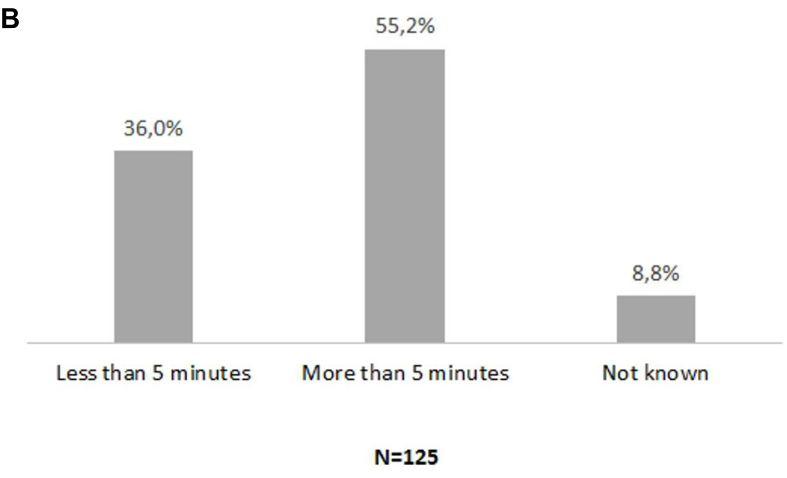

D

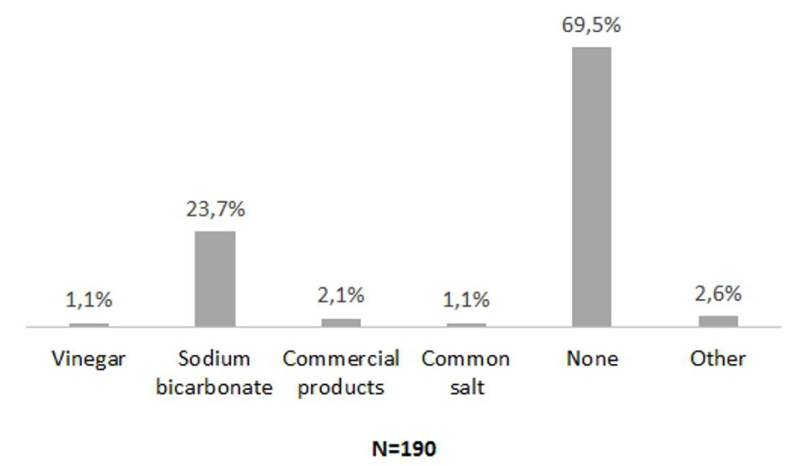

FIGURE 2 | Survey on domestic vegetable washing. (A) Vegetable washing methods, (B) Duration of vegetable washing, (C) Number of washing sessions, (D) Chemicals added to water. $\mathrm{N}$ indicates the number of respondents for each administered question. Percentage of respondents for each possible answer was indicated on the top of the histogram.

immersion of rocket in tap water three times; immersion of rocket in a solution of sodium bicarbonate. Interestingly immersion of rocket in a solution of vinegar and water was also used. All of these vegetable washing methods were examined in the second phase of the study.

\section{Survey of Industrial Raw Vegetable Washing}

Altogether, 20 ready-to-eat vegetable producers were interviewed. Two principal methods for washing vegetables were used in all the enrolled production plants. The two methods were: washing vegetables in a solution of sodium hypochlorite followed by rinsing with tap water; washing vegetables in a solution of peracetic and percitric acids, followed by rinsing with tap water. The concentrations of both solutions were not revealed, as they were trade secrets. Both industrial vegetable washing methods were examined in the second phase of the study. The solution of peracetic and percitric acids was provided by one of the producers.

\section{Effectiveness of Vegetable Washing Methods}

The $200 \mathrm{mg} / \mathrm{L}$ solution of sodium hypochlorite (WP6) resulted in a $2 \log$ reduction of Salmonella compared to the control
TABLE 1 $P$ values resulting from the linear mixed-effects model for pairwise comparison of vegetable washing protocols, in relation to the control, for $E$. vesicaria artificially contaminated by S. enterica at $10^{7} \mathrm{CFU} / \mathrm{g}$.

\begin{tabular}{lcccccc}
\hline & Control & WP1 & WP2 & WP3 & WP4 & WP5 \\
\hline WP1 & 0.799 & - & - & - & - & - \\
WP2 & 1 & 0.7332 & - & - & - & - \\
WP3 & 0.704 & 1 & 0.629 & - & - & - \\
WP4 & 0.748 & 1 & 0.676 & 1 & - & \\
WP5 & 0.744 & 0.0562 & 0.809 & 0.0350 & 0.043 & - \\
WP6 & $<0.001$ & $<0.001$ & $<0.001$ & $<0.001$ & $<0.001$ & $<0.001$ \\
\hline
\end{tabular}

$(p<0.001)$, and in a greater reduction of pathogen counts than all the other washing methods $(p<0.001$, Table 1). However, this effect was observed only in the presence of high Salmonella counts (7 Log CFU/g), but it was not observed in the scenario of low level contamination (3 Log CFU/g; Table 2). All the other washing methods resulted in non significant reductions of Salmonella counts compared to the control, in the presence of both high and low level contamination (Tables 1 and 2, Figure 3).

In the case of Listeria, results were consistent in the presence of both high and lower contamination levels, 7 and $6 \mathrm{Log} \mathrm{CFU} / \mathrm{g}$, respectively. All the washing methods effectively reduced Listeria 
TABLE 2 | $\boldsymbol{P}$ values resulting from the linear mixed-effects model for pairwise comparison of vegetable washing protocols, in relation to the control, for $E$. vesicaria artificially contaminated by S. enterica at $10^{3} \mathrm{CFU} / \mathrm{g}$.

\begin{tabular}{lcccccc}
\hline & Control & WP1 & WP2 & WP3 & WP4 & WP5 \\
\hline WP1 & 0.987 & - & - & - & - & - \\
WP2 & 1 & 0.979 & - & - & - & - \\
WP3 & 1 & 0.991 & 1 & - & - & - \\
WP4 & 0.998 & 0.837 & 0.999 & 0.996 & - & - \\
WP5 & 0.553 & 0.137 & 0.611 & 0.517 & 0.881 & - \\
WP6 & 0.832 & 0.998 & 0.788 & 0.858 & 0.480 & 0.029 \\
\hline
\end{tabular}

contamination compared to the control $(p<0.001)$ (Tables 3 and 4). Sodium hypochlorite solution (WP6) and the solution of peracetic and percitric acids (WP1) produced the greatest Listeria reductions: 2 and 1.5 logs, respectively (Tables 3 and 4, Figure 4).

As regards pairwise comparison between treatments, WP1 and WP6 displayed the best performances compared to WP2, WP4, WP5 $(p<0.001)$, and to WP3 $(p<0.1)$. Moreover, WP3 was more effective in reducing Listeria counts only compared to WP5.
TABLE 3 | $\boldsymbol{P}$ values resulting from the linear mixed-effects model for pairwise comparison of vegetable washing protocols, in relation to the control, for $E$. vesicaria artificially contaminated by $L$. monocytogenes at $10^{7} \mathrm{CFU} / \mathrm{g}$.

\begin{tabular}{lcccccc}
\hline & Control & WP1 & WP2 & WP3 & WP4 & WP5 \\
\hline WP1 & $<0.001$ & - & - & - & - & - \\
WP2 & $<0.001$ & $<0.001$ & - & - & - & - \\
WP3 & $<0.001$ & 0.001 & 0.170 & - & - & - \\
WP4 & $<0.001$ & $<0.001$ & 0.962 & 0.738 & - & - \\
WP5 & $<0.001$ & $<0.001$ & 0.772 & 0.002 & 0.193 & - \\
WP6 & $<0.001$ & 1 & $<0.001$ & 0.086 & $<0.001$ & $<0.001$ \\
\hline
\end{tabular}

\section{DISCUSSION}

In this work, the effectiveness of six washing procedures on $S$. enterica or L. monocytogenes artificially contaminated onto rocket was assessed. Among the sanitisers investigated, sodium hypochlorite, which has long been used to disinfect fresh produce (Beuchat et al., 1998), produced the largest reductions in microbial counts of both S. enterica and L. monocytogenes.

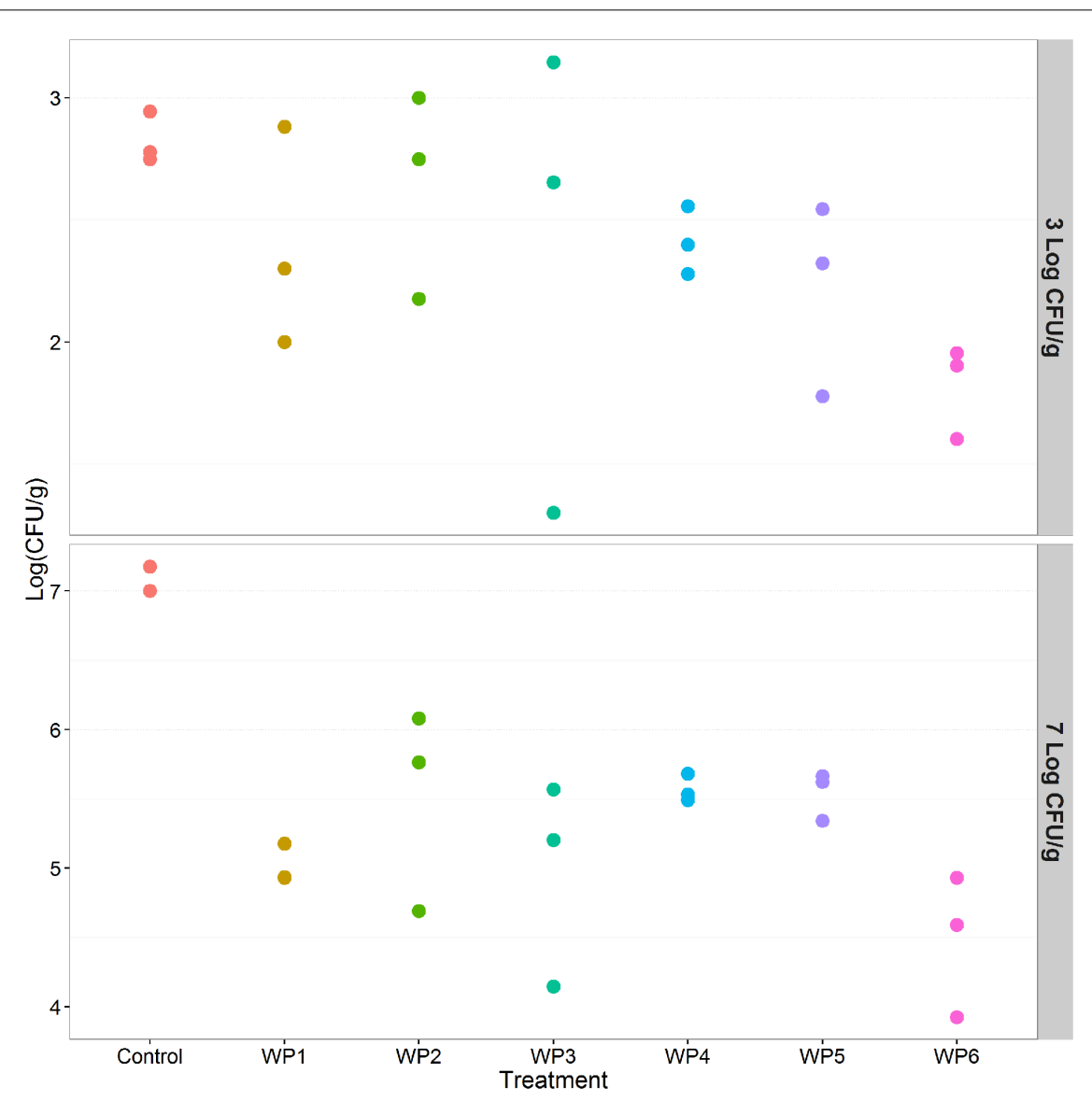

FIGURE 3 | Effect of the investigated vegetable washing protocols (WP1-WP6) on S. enterica counts after artificial contamination on raw E. vesicaria (Log scale). The upper panel shows results obtained in the low contamination condition (3 Log CFU/g); the lower panel shows results obtained in the high contamination condition (7 Log CFU/g). 
TABLE $4 \mid P$ values resulting from the linear mixed-effects model for pairwise comparison of vegetable washing protocols, in relation to the control, for $E$. vesicaria artificially contaminated by $L$. monocytogenes at $10^{6} \mathrm{CFU} / \mathrm{g}$.

\begin{tabular}{lcccccc}
\hline & Control & WP1 & WP2 & WP3 & WP4 & WP5 \\
\hline WP1 & $<0.001$ & - & - & - & - & - \\
WP2 & $<0.001$ & $<0.001$ & - & - & - & - \\
WP3 & $<0.001$ & 0.001 & 0.170 & - & - & - \\
WP4 & $<0.001$ & $<0.001$ & 0.962 & 0.738 & - & - \\
WP5 & $<0.001$ & $<0.001$ & 0.772 & 0.002 & 0.193 & - \\
WP6 & $<0.001$ & 1 & $<0.001$ & 0.086 & $<0.001$ & $<0.001$ \\
\hline
\end{tabular}

However, a non-significant effect was obtained from trials involving rocket with low levels of contamination. This was the main limitation of the present study and raises some concerns about washing procedure effectiveness against Salmonella in naturally contaminated vegetables.
In the case of Salmonella, $200 \mathrm{mg} / \mathrm{L}$ sodium hypochlorite significantly reduced bacterial counts, whilst in the case of Listeria, all sanitisers significantly reduced the counts, with sodium hypochlorite and combined peracetic and perchloric acids being the most effective. A difference in the effect against Salmonella and Listeria was observed also in the case of heavy metals such as silver used as antimicrobial (Losasso et al., 2014; Belluco et al., 2016). This could probably be due to the different structure and physiology of Salmonella and Listeria, being Gram negative and Gram positive, respectively.

Due to its low cost and ready availability, sodium hypochlorite is the most commonly used water disinfectant specifically applied in the fresh-cut produce industry for wash, spray, or flume waters (Gil et al., 2009). However, many disadvantages have been identified when this chemical is used to treat fresh produce. Sodium hypochlorite is highly corrosive and can form carcinogens following reaction with organic matter, particularly at high concentrations (Rodgers et al., 2004). The commonly applied free sodium hypochlorite concentrations

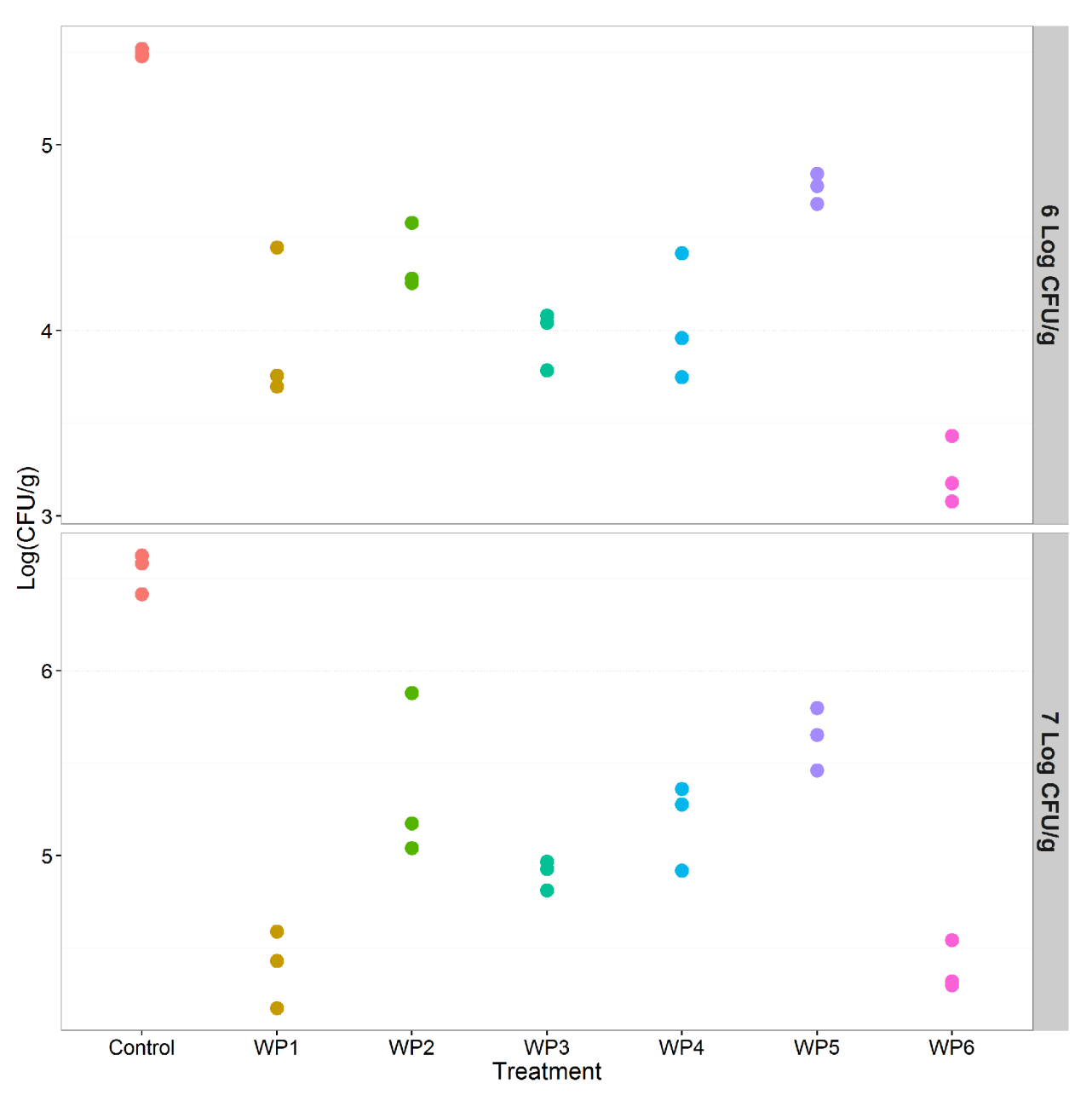

FIGURE 4 | Effect of the investigated vegetable washing protocols (WP1-WP6) on L. monocytogenes counts after artificial contamination on raw E. vesicaria (Log scale). The upper panel shows results obtained in the lower contamination condition (6 Log CFU/g); the lower panel shows results obtained in the higher contamination condition (7 Log CFU/g). 
in vegetable washing processes range from 50 to $200 \mathrm{mg} / \mathrm{L}$ (WHO, 2000). In addition, the use of sodium hypochlorite at high concentrations could generate chlorine gas, which could be harmful for consumers via inhalation. Furthermore, the potential for trihalomethane formation by sodium hypochlorite, depending on dose and organic matter content, is well known (WHO, 2000). Evidence on the formation of sodium hypochlorite by-products has been obtained by testing concentrations and/or contact times that would have unacceptable effects on product quality, or could not be applied at industrial scale due to environmental effects and personnel safety issues (WHO, 2000).

The present study demonstrated that the effective concentration of sodium hypochlorite to reduce both L. monocytogenes and S. enterica contamination on E. vesicaria was $200 \mathrm{mg} / \mathrm{L}$, suggesting potential harmful effects for consumers could occur. However, it is difficult to estimate the concentrations of sodium hypochlorite used in real life scenarios by consumers and, consequently, to exclude the risk deriving from consumer exposure to its by-products. Specifically, the amount of sodium hypochlorite added to water is often not measured, but it could exceed the safe level by an order of magnitude.

The current approach to ascertain the safety of foodstuffs is conceptually based on absence (or reduced presence) of foodborne pathogens in processed and unprocessed foodstuffs intended for human consumption, as legally required in the European Union Regulation (EC)2073/2005 (EC, 2005). However, sanitation practices applied to fulfill such safety criteria could change the microbial ecology of food matrices, thus resulting in potential positive and/or negative effects. In fact, due to the complexity of microbial metabolism and the interrelationships between various environmental factors, even apparently insignificant changes in the microbial environment can trigger food safety concerns or drive the evolution of pathogens. For example, the practice of rinsing foods with organic acids, with the aim of eliminating pathogens from the surface, could cause the evolution of acid-tolerant bacterial pathogens better able to survive in a host gastrointestinal tract (Cotter and Hill, 2003). The emergence of microorganisms with combined resistance to biocides and antimicrobial agents is a

\section{REFERENCES}

Bastos, M. S. R., de Fátima Ferreira Soares, N., José de Andrade, N., Cristina Arruda, A., and Elesbão Alves, R. (2005). The effect of the association of sanitizers and surfactant in the microbiota of the Cantaloupe (Cucumis melo L.) melon surface. Food Control 16, 369-373. doi: 10.1016/j.foodcont.2004. 04.002

Belluco, S., Losasso, C., Rigo, L., Conficoni, D., Cibin, V., Segato, S., et al. (2016). Silver nanoparticles as antibacterial towards Listeria monocytogenes. Front. Microbiol 7:307. doi: 10.3389/fmicb.2016.00307

Berger, C. N., Sodha, S. V., Shaw, R. K., Griffin, P. M., Pink, D., Hand, P., et al. (2010). Fresh fruit and vegetables as vehicles for the transmission of human pathogens. Environ. Microbiol. 12, 2385-2397. doi: 10.1111/j.14622920.2010.02297.x

Beuchat, L. R., Nail, B. V., Adler, B. B., and Clavero, M. R. S. (1998). Efficacy of spray application of chlorinated water in killing pathogenic bacteria on raw apples, tomatoes, and Lettuce. J. Food Prot. 61, 1305-1311. public health challenge. To date, much evidence has shown that biocides, used indiscriminately in an increasing number of applications, can also play a role in the development (or selection) and dissemination of biocide- and antibiotic-resistant pathogenic bacteria (Dancer, 2014; Tacconelli et al., 2014; Vergnano, 2015).

\section{CONCLUSION}

Correct vegetable washing practices, both at industrial and consumer levels, are critical to circumvent the phenomena described above. Clearly, this indicates the importance of proper communication campaigns targeting consumers on the correct and safe use of sanitation chemicals during vegetable washing for food safety purposes.

\section{AUTHOR CONTRIBUTIONS}

APe and SB conceived the experiments and conducted the experiments, CL analysed the results and wrote the manuscript, IP performed data analysis, APi conducted the experiments, DC, $\mathrm{RM}$, and AR conceived the experiments and analysed the results. All authors reviewed the manuscript.

\section{FUNDING}

This work was supported by the Ministry of Health, IT (project code RC IZSVe 09/11).

\section{ACKNOWLEDGMENTS}

The authors wish to thank the ABSeeS Scientific English Editorial Services (http://absees-editorial.my-free.website/contact-us) for the linguistic revision of the manuscript. The funder had no role in study design, data collection and interpretation, or the decision to submit the work for publication.

Brandl, M. T. (2006). Fitness of human enteric pathogens on plants and implications for food safety. Annu. Rev. Phytopathol. 44, 367-392. doi: 10.1146/annurev.phyto.44.070505.143359

Chen, Z., and Jiang, X. (2014). Microbiological safety of chicken litter or chicken litter-based organic fertilizers: a review. Agriculture 4, 1-29. doi: 10.3390/agriculture4010001

Cotter, P. D., and Hill, C. (2003). Surviving the acid test: responses of grampositive bacteria to low pH. Microbiol. Mol. Biol. Rev. 67, 429-453. doi: 10.1128/MMBR.67.3.429-453.2003

Dancer, S. J. (2014). Controlling hospital-acquired infection: focus on the role of the environment and new technologies for decontamination. Clin. Microbiol. Rev. 27, 665-690. doi: 10.1128/CMR. 00020-14

Denis, N., Zhang, H., Leroux, A., Trudel, R., and Bietlot, H. (2016). Prevalence and trends of bacterial contamination in fresh fruits and vegetables sold at retail in Canada. Food Control 67, 225-234. doi: 10.1016/j.foodcont.2016. 02.047 
EC (2005). COMMISSION REGULATION (EC) No 2073/2005 of 15 november 2005 on microbiological criteria for foodstuffs implementing regulation (EC) No 2160/2003 of the European parliament and of the council as regards requirements for the use of specific control methods. Official J. Eur. Union L $338,1-26$.

EFSA (2015). The European union summary report on trends and Sources of zoonoses, zoonotic agents and food-borne outbreaks in 2014. EFSA J. 13, 4329. doi: 10.2903/j.efsa.2015.4329

Faccio, E., Costa, N., Losasso, C., Cappa, V., Mantovani, C., Cibin, V., et al. (2013). What programs work to promote health for children? Exploring beliefs on microorganisms and on food safety control behavior in primary schools. Food Control 33, 320-329. doi: 10.1016/j.foodcont.2013.03.005

Francis, G. A., Thomas, C., and O'beirne, D. (1999). The microbiological safety of minimally processed vegetables. Int. J. Food Sci. Technol. 34, 1-22. doi: 10.1046/j.1365-2621.1999.00253.x

Franz, E., and van Bruggen, A. H. C. (2008). Ecology of E. coli O157:H7 and Salmonella enterica in the primary vegetable production chain. Crit. Rev. Microbiol. 34, 143-161. doi: 10.1080/10408410802357432

Gil, M. I., Selma, M. V., López-Gálvez, F., and Allende, A. (2009). Fresh-cut product sanitation and wash water disinfection: problems and solutions. Int. J. Food Microbiol. 134, 37-45. doi: 10.1016/j.ijfoodmicro.2009.05.021

Grimont, P. A. D., and Weill, F.-X. (2007). Antigenic Formulae of the Salmonella Serovars. Paris: Institut Pasteur.

Heaton, J. C., and Jones, K. (2008). Microbial contamination of fruit and vegetables and the behaviour of enteropathogens in the phyllosphere: a review. J. Appl. Microbiol. 104, 613-626. doi: 10.1111/j.1365-2672.2007. 03587.x

Hellström, S., Kervinen, R., Lyly, M., Ahvenainen-Rantala, R., and Korkeala, H. (2006). Efficacy of disinfectants to reduce Listeria monocytogenes on precut iceberg lettuce. J. Food Prot. 69, 1565-1570.

Hilgren, J. D., and Salverda, J. A. (2000). Antimicrobial efficacy of a peroxyacetic/octanoic acid mixture in fresh-cut-vegetable process waters. J. Food Sci. 65, 1376-1379. doi: 10.1111/j.1365-2621.2000.tb10615.x

ISO (2004a). ISO 11290-2:1998/Amd 12004 - Modification of the Enumeration Medium. Geneva: ISO.

ISO (2004b). ISO 6579:2002/Cor.1 2004 (E) - Microbiology of Food and Animal Feeding Stuffs. Horizontal Method for the Detection of Salmonella spp. Geneva: ISO.

Liao, C.-H., and Sapers, G. M. (2000). Attachment and growth of Salmonella Chester on apple fruits and in vivo response of attached bacteria to sanitizer treatments. J. Food Prot. 63, 876-883.

Lomonaco, S., Nucera, D., and Filipello, V. (2015). The evolution and epidemiology of Listeria monocytogenes in Europe and the United States. Infect. Genet. Evol. 35, 172-183. doi: 10.1016/j.meegid.2015.08.008

Losasso, C., Belluco, S., Cibin, V., Zavagnin, P., Mičetić, I., Gallocchio, F., et al. (2014). Antibacterial activity of silver nanoparticles: sensitivity of different Salmonella serovars. Front. Microbiol. 5:227. doi: 10.3389/fmicb.2014.00227
Losasso, C., Cappa, V., Cibin, V., Mantovani, C., Costa, N., Faccio, E., et al. (2013). Food safety and hygiene lessons in the primary school: implications for risk-reduction behaviors. Foodborne Pathog. Dis. 11, 68-74. doi: 10.1089/fpd.2013.1598

Losasso, C., Cibin, V., Cappa, V., Roccato, A., Vanzo, A., Andrighetto, I., et al. (2012). Food safety and nutrition: improving consumer behaviour. Food Control 26, 252-258. doi: 10.1016/j.foodcont.2012.01.038

Ragaert, P., Devlieghere, F., and Debevere, J. (2007). Role of microbiological and physiological spoilage mechanisms during storage of minimally processed vegetables. Postharvest Biol. 44, 185-194. doi: 10.1016/j.postharvbio.2007.01.001

Rodgers, S. L., Cash, J. N., Siddiq, M., and Ryser, E. T. (2004). A comparison of different chemical sanitizers for inactivating Escherichia coli O157:H7 and Listeria monocytogenes in solution and on apples, lettuce, strawberries, and cantaloupe. J. Food Prot. 67, 721-731.

Sy, K. V., McWatters, K. H., and Beuchat, L. R. (2005). Efficacy of gaseous chlorine dioxide as a sanitizer for killing Salmonella, yeasts, and molds on blueberries, strawberries, and raspberries. J. Food Prot. 68, 1165-1175.

Tacconelli, E., Cataldo, M. A., Dancer, S. J., De Angelis, G., Falcone, M., Frank, U., et al. (2014). ESCMID guidelines for the management of the infection control measures to reduce transmission of multidrug-resistant gram-negative bacteria in hospitalized patients. Clin. Microbiol. Infect. 20, 1-55. doi: 10.1111/14690691.12427

UNI EN ISO (2005). UNI EN ISO 11290-1:2005 - Microbiology of Food and Animal Feeding Stuffs - Horizontal Method for the Detection and Enumeration of Listeria Monocytogenes - Part 1: Detection Method. Geneva: ISO.

Vergnano, S. (2015). Decolonization and decontamination. Curr. Opin. Infect. Dis. 28, 207-214. doi: 10.1097/QCO.0000000000000164

Weissgerber, T. L., Milic, N. M., Winham, S. J., and Garovic, V. D. (2015). Beyond bar and line graphs: time for a new data presentation paradigm. PLoS Biol. 13:e1002128. doi: 10.1371/journal.pbio.1002128

WHO (2000). Environmental Health Criteria 216: Disinfectants and Disinfectant By-products. Geneva: World Health Organization.

WHO/FAO (2003). Diet, nutrition and the prevention of chronic. World Health Organ. Tech. Rep. Ser. 916, i-viii,1-149.

Conflict of Interest Statement: The authors declare that the research was conducted in the absence of any commercial or financial relationships that could be construed as a potential conflict of interest.

Copyright (C) 2016 Pezzuto, Belluco, Losasso, Patuzzi, Bordin, Piovesana, Comin, Mioni and Ricci. This is an open-access article distributed under the terms of the Creative Commons Attribution License (CC BY). The use, distribution or reproduction in other forums is permitted, provided the original author(s) or licensor are credited and that the original publication in this journal is cited, in accordance with accepted academic practice. No use, distribution or reproduction is permitted which does not comply with these terms. 